Ankomah, E.N., Ayarkwa, J., and Agyekum, K. (2018). "Conceptual framework for capability and capacity building of SMEs for lean construction adoption." In: Proc. $26^{\text {th }}$ Annual Conference of the International. Group for Lean Construction (IGLC), González, V.A. (ed.), Chennai, India, pp. 231-239. DOI: doi.org/10.24928/2018/0495. Available at: www.iglc.net

\title{
CONCEPTUAL FRAMEWORK FOR CAPABILITY AND CAPACITY BUILDING OF SMES FOR LEAN CONSTRUCTION ADOPTION
}

\author{
Emmanuel N. Ankomah', Joshua Ayarkwa², and KofiAgyekum
}

\begin{abstract}
Lean construction (LC) is a production system with the potential to deliver exceptional performance within any organisation. LC is possible solution to the many problems faced by construction Small and Medium Enterprises (SMEs). However, Construction SMEs lack the needed resources which constraint their lean implementation efforts. A conceptual framework for capability and capacity building of Construction SMEs is developed based on the Toyota Way model.

This research was conducted using systematic review of literature. The review suggests there is the need to build the capability and capacity of SMEs to fully adopt the LC philosophy. SMEs provide a challenging context for the implementation of LC due to their lack of the needed resources.

The outcome of this study is to focus attention on building the capability and capacity of Construction SMEs to fully adopt LC. This will help reduce the incidence of high failure rates of LC implementation recorded amongst SMEs. Previous works have concentrated on what SMEs can and should do within their limited capacity. However, the use of the isolated tools and practices fail because lean is a system that has to be implemented holistically. A conceptual framework for building the capability and capacity of SMEs for LC adoption is therefore proposed.
\end{abstract}

\section{KEYWORDS}

SMEs, Lean Construction, Capability and Capacity Building, Process, Value.

Lecturer, Building Tech. Dept., Sunyani Technical University, Kumasi, Ghana, +233 244590 709,

bd310nsiah@gmail.com

2 Professor, Building Tech. Dept., KNUST, Kumasi, Ghana, +233 246010 870, ayarkwajosh@yahoo.com

3 Lecturer, Building Tech. Dept., KNUST, Kumasi, Ghana, +233 246761 879,

agyekum.kofi1@gmail.com 


\section{INTRODUCTION}

SMEs are critical in the structure of the construction industry (Oforiand Toor 2012) as they form majority of the firms (Gyadu-Asiedu 2009; Amoah et al. 2011).In the Ghanaian context, construction SME is a family run domestic contractor with 199 employees as the upper threshold and 10 employees as the lower threshold (Kheni 2008).Small construction firms in Ghana constitute about $95 \%$ of contractors, over $90 \%$ of the job market, and nearly $80 \%$ of all short-term employment (Amoah et al. 2011).Globally, the importance of this critical sector cannot be overemphasized.

In spite of the significant contributions construction SMEs make to the economies of both developed and developing nations, they face a lot of challenges that affect their capacity (Amoah et al. 2011). Accordingly, implementing LC has become a challenge for SMEs (Marasini et al. 2014), as these firms are constrained in terms of the resources (Marasini et al. 2014; Netland 2016). This has led to a concentration on what SMEs can and should do within their available resources. In the work of Rose et al. (2011), the authors argued that SMEs should go in for least costly tools, which is well within their capacity. In other work, such as Matt and Rauch (2013), it was suggested that SMEs should use principles declared to be suitable for them. However, in most cases the use of isolated practices leads to a failure of lean implementation (Lathin and Mitchell 2001). These previous works have fallen short of looking at how SMEs capability and capacity can be built to fully implement the lean philosophy. More so, the benefits of a full implementation cannot be compared with an implementation of just a few tools (Netland 2016; Liker 2004). The study therefore seeks to develop a conceptual framework for capability and capacity building of SMEs for LC adoption.

\section{RESEARCH METHODOLOGY}

Systematic literature review was utilized because of the rigorous and transparent form of the review (Okoli and Schabram 2010). This study follows the comprehensive stages for the systematic review developed by Tranfield et al. (2003).

The initial descriptors used for the literature search were "Lean construction," "construction SMEs," "Lean and construction SMEs. A total of 114 articles were initially identified from the search. However, not all of the 114 papers presented research arguments on the issue of LC and SMEs. The papers were briefly examined to filter out irrelevant articles. A total of 63 papers were finally selected to be valid for the study. A conceptual framework is developed based on the analysis of these selected papers.

\section{LEAN CONSTRUCTION IMPLEMENTATION WITHIN SMES}

LC techniques offer the potential to minimize, if not entirely eliminate, non-value adding activities (Salem et al. 2005). Thus, LC is about the elimination of all non-value-added steps in a process (Arroyo and Gonzalez 2016). Several studies, such as Cho and Ballard (2011), Bhamuand Sangwan (2014) point to the significant benefits of LC to the incidence of low productivity, low quality of works, increased construction cost, low job satisfaction and waste generation within construction processes. LC is a possible solution 
to the many problems faced by construction SMEs (Sage et al. 2012; Bhamu and Sangwan 2014).

SMEs are generally constrained by their management, resources and organisational culture and structure that affect their Lean efforts (Achanga et al. 2006; Panizzolo et al. 2012). For instance, human resources in SMEs are weak in terms of their knowledge and skills. There are a number of issues that affect SMEs' ability to recruit, motivate and retain the best of talents (Darkwah 2014). Top management support, commitment and buy-in is a critical success factor in LC implementation (Al-Najem et al. 2012), however top management in SMEs normally will not acknowledge the need for change. It is difficult to succeed in LC without a healthy culture. In UK for instance, only $10 \%$ of the firms succeed in their lean implementation efforts. The reasons for such a huge failure are culture and management (Taleghani2010). LC requires a culture of employee empowerment, teamwork and enhanced relationship with suppliers (Al-Najem et al. 2012). This is mostly lacking within SMEs, as employees are not usually empowered and relationship with suppliers is mostly adversarial. Top down leadership style that is a characteristic of Construction SMEs is a cultural barrier that inhibits lean implementation.

\section{A REVIEW OF LEAN FRAMEWORKS}

Over the years there have been a number of models that looked into the possible implementation of lean production principles. Anand and Kodali (2010) examined approximately thirty (30) frameworks for lean production. The authors concluded that none was comprehensive. In view of that, they proposed a framework consisting of 65 lean elements, taking into consideration the shortcomings of the previous frameworks. Chay et al. (2015) posit that the framework developed by Anand and Kodali (2010) is too sophisticated and does not address "why" aspect of the implementation of lean principles. The authors also reviewed frameworks developed between 2010-2013. The study discovered that lean production frameworks developed after the work of Anand and Kodali (2010) has disregarded the soft elements of Lean production. Similarly, Gao and Low (2014) reviewed various frameworks for LC. The authors proposed an alternative framework for LC implementation, taking into consideration all aspects of the organisation (both the social and technical).

Consequently, frameworks have been developed specifically for the SME sector (for instance, Amad-Uddin, 2011; Rose et al. 2011; and Belhadi et al. 2016). The strength of these frameworks lies in its consideration of both the soft and hard aspects of lean implementation. These lean production frameworks developed specifically for SMEs overlook the aspects of capacity building, although authors acknowledge the lack of capacity for lean implementation within the SME sector. These frameworks instead propose feasible lean tools that can be implemented within the limited capacity of SMEs, but failed to look at how SMEs can be supported to fully implement the lean system. Similarly, promoting LC to SMEs and developing the capability and capacity of SMEs to deploy LChas received little attention within the LC Community. Considering the capability and capacity challenges of SMEs, any framework which can be successfully adopted by SMEs should take into consideration the capability and capacity needs of 
these firms and where possible support systems to cushion them to adopt these principles. More so, lean is a system that has to be implemented holistically in principles and techniques, therefore there will there be a need for a framework that takes into consideration capability and capacity building of SMEs to fully adopt the lean system.

\section{DEVELOPMENT OF THE CONCEPTUAL FRAMEWORK}

In assessing LC frameworks Gao and Low (2014), posit that 'process-focus' thinking is still the major focus of the LC frameworks reviewed. This is because the implementation of lean principles on the "shop floor" can result in immediate improvements (Liker2004).

In view of the shortcomings of the LC frameworks, the study proposed the " $4 \mathrm{P}$ Model" of the Toyota Way. This model was proposed to resolve some of the fundamental limitations of the frameworks that are available within the LC domain. The 4P model of the Toyota Way was introduced as an alternative means of interpreting LC (Gao and Low 2014). This study therefore in developing the conceptual framework for SMEs adopts the "4P Model" developed by Liker (2004)and proposed by Gao and Low (2014) for LC implementation.

\section{JUSTIFICATION FOR THE USE OF"4P MODEL"}

Many authors have argued that lean is a social and a technical system(Liker 2004; Shah and Ward 2007; Low and Gao 2011). Accordingly, the 4P model would be a suitable choice for LC implementation (Gao and Low 2014). In the application of lean principles, the focus has largely been on the technical aspects of production (Liker 2004), while ignoring the implications for the people related aspects (Green 2002). The technicalaspect fails or underperforms if the social or human related aspects are ignored. This is the case because the real issues during the process are human cantered (Chay et al. 2015). In other words, it is also imperative to create a healthier people system. This assertion is in line with Matsui (2007) who suggests that the effectiveness of technical practices is appreciably increased when equally teamed with the soft practices.

The "technical-focused" thinking significantly restricts the degree of improvement that can be achieved (Emiliani and Stec 2005; Bhasin and Burcher 2006). Accordingly, the "4P model" is a comprehensive model for LC implementation (Liker 2004; Gao 2013; Gao and Low 2014). The "4P model" comprises 14 principles within four layers with each layer serving as an individual model in itself. The next section discusses the "4P model" in detail toward the framework development.

\section{"4P MODEL" OF THE TOYOTA WAY}

Liker (2004) used a pyramidal model, which comprises an outline of Toyota's principles. These principles are grouped in four broad categories and each contains important subprinciples:

- Long term Philosophy (Philosophy).

- The right Process will produce the right results (Process). 
- Add value to the organization by developing your People and Partners (People/Partners).

- Continuously solving root problems drives organizational learning (Problem Solving).

According to Liker (2004), these four broad categories have fourteen principles. The foundation of the pyramid is the management philosophy, which is based on long-term decisions, even at the expense of short-term financial goals. Following from that are the right processes producing the right results. Ultimately, production flow is standardized and visualized which helps in identifying problems. The next level places respect on people and partners, while challenging and growing them. The last layer of the pyramid is the problem solving philosophy by using various improvement tools such as kaizen and genchigenbutsu (going to see for yourself).

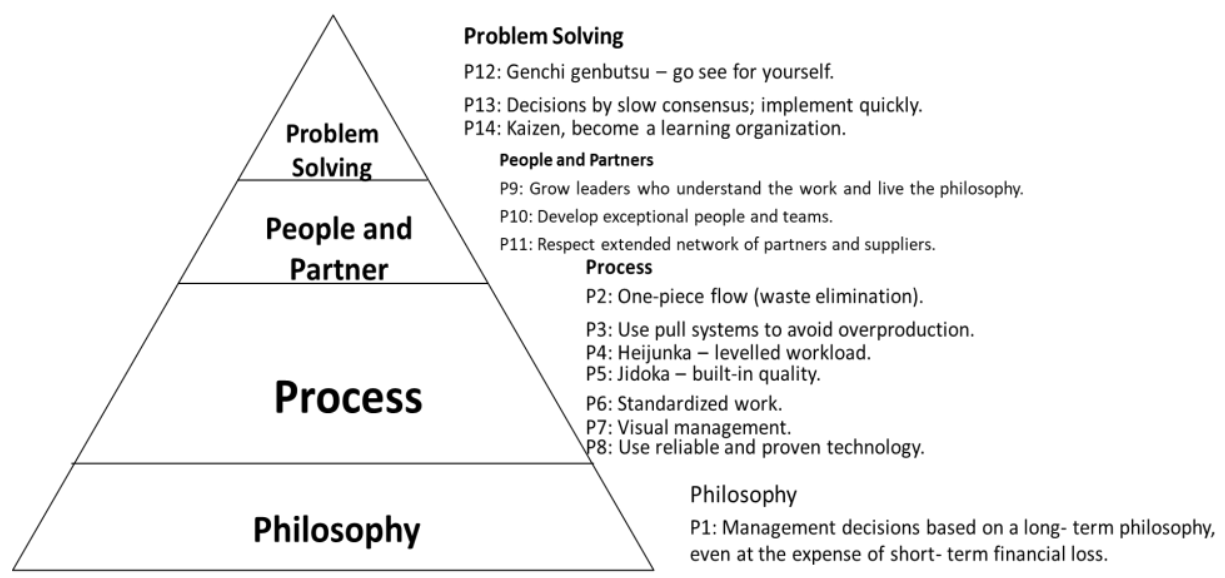

Figure 1: 4P model of the Toyota Way (Source: Liker, 2004)

\section{CONCEPTUAL FRAMEWORKFOR CAPABILITY AND CAPACITYBUILDING OF SMES}

In developing the framework as can be seen in Figure 2, the 4P Model was used as the basis for LC implementation. LC tools identified in the literature were linked to the model. The next level assesses the status of implementation and challenges in LC implementation by SMEs. This leads to the capability and capacity needs of these SMEs. Following from these needs is developing intervention for capability and capacity building of SMEs. These interventions are considered from the Systematic Approach. The System Approach consists of four levels; the individual, organizational, industry and state level. In essence, the interventions are taken from the level of the individuals to the organisation, then at the industry and finally at the state level. This leads finally to policies and plans for LC implementation by these SMEs. This framework proposes a strategy for a successful LC implementation by SMEs taking into consideration their capability and capacity needs. 
The customer of the framework is the construction industry sector. The conceptual framework eventually leads to policies and plans for building the capability and capacity of SMEs for LC adoption. These policies and plans emanating from the needs of SMEs will act as guidelines to the construction industry sector in building the capability and capacity of individual SMEs for broader application of LC principles. Since this framework incorporates the specific needs of SMES, it will give this important and crucial sector more capabilities and capacity for adopting wider LC principles. Ultimately this intervention will lead to an improvement in the performance of SMEs resulting in a huge impact within the industry and the economy of any country.

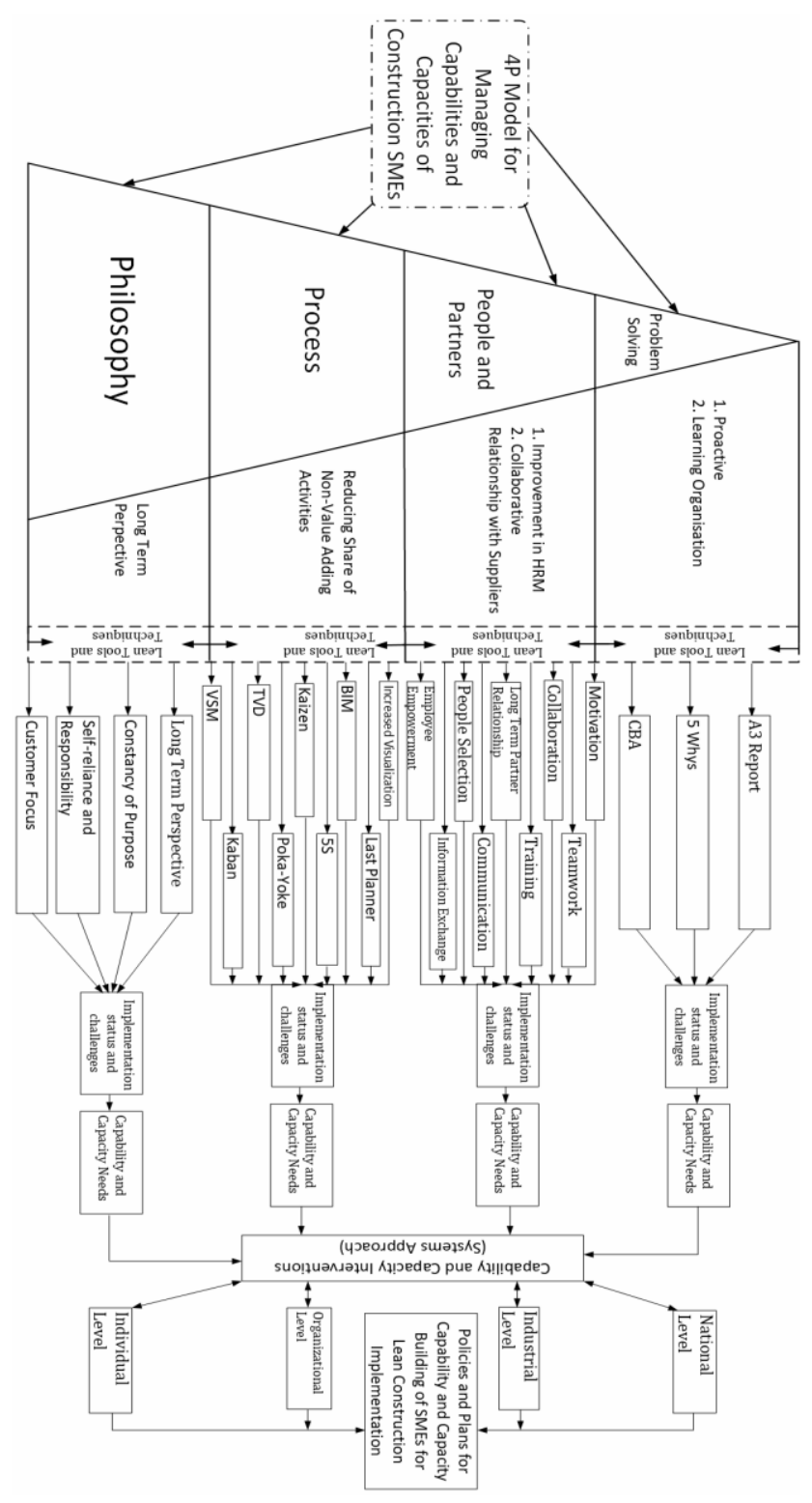

Figure 2: Conceptual framework for Capability and Capacity Building of SMEs 


\section{CONCLUSIONS}

The growth of the SME sector for any country is of vital significance irrespective of its state of development. SMEs relevance and importance can be seen in all aspects of the socioeconomic lives of countries. Notwithstanding their contributions to the economies of countries worldwide, SMEs are faced with fundamental problems. This, in effect has led to widespread underperformance within this sector and a high attrition rate. LC as a management philosophy is acknowledged as an established set of principles to help organisations to be effective, efficient and maximize value to clients. Therefore, the adoption of LC within the SME sector is an important topic area to examine especially as there is a lower application. LC implementation within this sector is challenging, as these firms lack the needed resources to fully implement this management philosophy.

Several frameworks have been developed for an easy implementation of LC within this sector. Although these frameworks were developed specifically for this critical sector, it has largely overlooked the elements of capability and capacity building. A successful adoption of lean by construction SMEs will heavily depend on their capability and capacity for easy implementation. To overcome this gap this study has developed a conceptual framework for building the capability and capacity of Construction SMEs to fully adopt the LC philosophy. This will help reduce the high incidence of failure recorded in LC implementation. Eventually leading to an improvement in the construction industry as a whole, as SMEs form majority of firms. This study serves as a basis for an on-going PhD that aims at developing a framework for capability and capacity building of Small and Medium Building Contractors for lean adoption to enhance their performance.

\section{REFERENCES}

Achanga, P., Shehab, E., Roy, R. and Nelder, G. (2006), "Critical success factors for Lean implementation within SMEs", Journal of Manufacturing Technology Management, 17(4), 460-471.

Al-Najem, M., Dhakal, H., \& Bennett, N. (2012), "The role of culture and leadership in lean transformation: a review and assessment model", International Journal of Lean Thinking, 3(1), 119-138.

Amad-Udin. (2011), "A conceptual design for lean manufacturing system and its implementation in SME and LE", in Robotics and Factories of the Future proceedings of the 26th International Conference on CAD/CAM, 2011, Kuala Lumpur, Malaysia, pp. 289-296

Amoah, P., Ahadzie, D. K., \& Danso, A., (2011), "The factors affecting construction performance in Ghana: The perspective of small-scale building contractors", The Ghana Surveyor, 4(1), pp. 41-48.

Anand, G. \& Kodali, R. (2010), "Analysis of Lean Manufacturing Frameworks"; Journal of Advanced Manufacturing Systems. 09(01): 1-30

Arroyo, P. and Gonzalez, V. 2016. "Rethinking Waste Definition to Account for Environmental and Social Impacts." In: Proc. 24rdAnn. Conf. of the Int'1. Group for 
Lean Construction, 20-22 July, Boston, MA, USA, sect.10 pp. 13-22, Available at: <www.iglc.net>.

Ballard, G., (2011), “Target Value Design: Current Benchmark", Lean Construction Journal, pp. 79-84

Belhadi, A. and Touriki, F.E., (2016), "A framework for effective implementation of lean production in Small and Medium-sized Enterprises", Journal of Industrial Engineering and Management, 9(3), pp.786-810.

Bhamu, J., and Sangwan, K. S., (2014), "Lean Manufacturing: Literature Review and Research Issues", International Journal of Operations \& Production Management, Vol. 34 No. 7, pp. 876-940

Bhasin, S. and Burcher, P., (2006), "Lean viewed as a philosophy", Journal of manufacturing technology management, 17(1), pp.56-72.

Chay, T., Xu, Y., Tiwari, A. and Chay, F., (2015), "Towards lean transformation: the analysis of lean implementation frameworks", Journal of Manufacturing Technology Management, 26(7), pp.1031-1052.

Cho, S., and Ballard, G., (2011), "Last planner and integrated project delivery", Lean Construction Journal, 2011 issue, 67-78.

Darkwah, V., (2014), "Examining the Recruitment and Selection Practices of Family Owned Small Medium Enterprises In The Kumasi Metropolis", Master Thesis Submitted to the

Emiliani, M.L. and Stec, D.J. (2005), "Leaders lost in transformation", Leadership and Organization Development Journal, 26 (5): 370-387.

Gao, S., (2013), "The Toyota Way Model: An Implementation Framework for Large Chinese Construction Firms", Doctoral Thesis Submitted to National University of Singapore

Gao, S., and Low, S.P., (2014), "The Toyota Way model: an alternative framework for lean construction", Total Quality Management \& Business Excellence, 25(5-6), pp.664-682.

Green, S. D. (1999), "The missing arguments of lean construction", Construction Management and Economic, 17 (2): 133-137.

Green, S.D., (2002), "The human resource management implications of lean construction: critical perspectives and conceptual chasms", Journal of Construction Research, 3(01), pp. $147-165$

Gyadu-Asiedu, W. (2009), "Assessing Construction Project Performance in Ghana: Modelling Practitioners' and Clients' Perspectives", Doctorate Thesis Submitted to the Technology University of Eindhoven

Kheni, N. A., (2008): Impact of Health and Safety Management on Safety Performance of Small and Medium-Sized Construction Businesses in Ghana, UK: A Doctoral Thesis submitted in partial fulfilment of the requirements for the award of Doctor of Philosophy of Loughborough University

Lathin, D. and Mitchell, R. (2001), "Learning from mistakes", Quality Progress, Vol. 34 No. 6, pp. 39-45.

Liker, J.K., (2004), “The Toyota Way: 14 Management Principles from the World's Greatest Manufacturer", New York: McGraw-Hill. 
Low, S.P. and Gao, S. (2011), "The application of the Just-in-Time philosophy in the Chinese construction industry", Journal of Construction in Developing Countries, 16 (1): 91-111

Marasini, B., Kharel, S., Deo, K. N., Gupta, B., (2014), “A Model for Implementation of Lean Manufacturing In Indian Small Scale Industries", International Journal of Science, Engineering and Technology Research (IJSETR), Volume 3, Issue 5,

Matsui, Y. (2007), "An empirical analysis of just-in-time production in Japanese manufacturing companies", International Journal of Production Economics, 108(1-2),

Matt, D. and Rauch, E. (2013), "Implementation of Lean Production in small sized Enterprises", 8th CIRP Conference on Intelligent Computation in Manufacturing Engineering, 12, 420-425

Netland, H. T., (2016), "Critical Success Factors for Implementing Lean Production: The Effect of Contingencies", International Journal of Production Research Vol. 54, Iss. 8,2016

Ofori, G., \& Toor, S. R. (2012), "Leadership development for construction SMEs", In EPOC 2012 Conference, Working Paper Proceedings, Engineering Project Organizations Conference, Rheden, Netherlands (pp. 10-12).

Okoli, C. \& Schabram, K. (2010), "Working Papers On Information Systems A Guide To Conducting A Systematic Literature Review Of Information Systems Research" Working Papers on Information Systems. 10(26): 1-51.

Panizzolo, R., Garengo, P., Sharma, M. and Gore, A., (2012), "Lean Manufacturing in Developing Countries: Evidence from Indian SMEs", Production Planning \& Control, 23(10-11), pp. 769-788.

Rose, A., Deros, B., Rahman, M., and Nordin, N., (2011), "Lean Manufacturing Best Practices in SMEs", In the proceedings of the International Conference on Industrial Engineering and Operations Management (pp. 22-24). Kuala Lumpur, Malaysia: IEOM Research Solutions Pty Ltd.

Sage, D., Dainty, A., and Brookes, N., (2012), "A 'strategy-as-practice' exploration of Lean construction strategizing", Building Research \& Information V.40(2), pp.221230.

Salem, O., Solomon, J., Genaidy, A. and Luegring, M., (2005), "Site implementation and assessment of lean construction techniques", Lean Construction Journal, 2(2), 1-21.

Shah, R. and Ward, P.T., (2007), "Defining and developing measures of lean production", Journal of Operations Management, 25 (4):785-805

Taleghani, M., (2010), "Success and Failure Issues to Lead Lean Manufacturing Implementation", World Academy of Science, Engineering and Technology, 615-618.

Tranfield, D., Denyer, D. \& Smart, P. (2003), "Towards A Methodology For Developing Evidence-Informed Management Knowledge By Means Of Systematic Review", British Journal of Management. 14: 207-222 